\title{
Pneumococcal capsular antigen detection and pneumococcal serology in patients with community acquired pneumonia
}

\author{
W G Boersma, A Löwenberg, Y Holloway, H Kuttschrütter, J A M Snijder, G H Koëter
}

\begin{abstract}
Background Methods to determine the microbial cause of community acquired pneumonia include detection of pneumococcal antigen and measurement of pneumococcal capsular antibody response. Their usefulness compared with conventional microbiological techniques was investigated in patients with pneumonia, some of whom had been treated with antibiotics.
\end{abstract}

Methods Pneumococcal capsular antigen was detected by latex agglutination in sputum and the results compared prospectively with results of conventional microbiological techniques in 90 patients with community acquired pneumonia. Serum, urine, and pleural fluid samples were also tested for antigen. Serum pneumococcal capsular antibody titres were measured.

Results A diagnosis was established by conventional microbiological techniques in 53 patients, 30 of whom had pneumococcal pneumonia. The sensitivity of antigen detection in first day sputum specimens $(n=18)$ in those with pneumococcal pneumonia was $94 \%$; antigen was present in 23 of the 27 patients who produced representative sputum on admission and during follow up. The specificity of antigen detection in sputum in patients with non-pneumococcal pneumonia and lung infarction was $87 \%$. Antigen was present in 12 of 25 patients with pneumonia of unknown aetiology who produced representative sputum. Antigen was rarely detected in serum and urine, but was present in pleural fluid in three of four patients with pneumococcal pneumonia and in all four patients with pneumonia of unknown aetiology. Pneumococcal antigen remained detectable in patients treated with antibiotics. Pneumococcal capsular antibody detection was as specific ( $85 \%)$ as antigen detection, but had a lower sensitivity (50\%).

Conclusion Pneumococcal antigen detection in sputum or pleural fluid is of value in making a rapid diagnosis and provides an additional diagnostic result in patients with pneumococcal pneumonia, especially those receiving antibiotic treatment.

Despite the availability of antibiotic treatment community acquired pneumonia is still a severe, life threatening illness. ${ }^{1-5}$ It is often difficult to establish a causative agent rapidly because of a lack of good quality sputum, pretreatment with antibiotics and the delay caused by serological testing.

Although sputum may be contaminated with oropharyngeal flora, a Gram stained smear is of diagnostic value, especially when the leucocyte to squamous epithelial cell ratio is $>5 .{ }^{67}$ Washing sputum to reduce contamination may improve the reliability of the method. ${ }^{8-10}$

To improve the diagnostic yield in patients with pneumonia methods to detect pneumococcal antigen in sputum and other body fluids have been developed. ${ }^{11-16}$ Antigen detection increases the diagnosis of pneumococcal infection, especially in patients with sputum samples with no bacteria in Gram stained smears and may influence the choice of antibiotic treatment. ${ }^{17-20} \mathrm{We}$ compared the results of pneumococcal capsular antigen detection in washed sputum, serum, urine, and pleural fluid specimens with those of conventional microbiological culture techniques on patients in hospital with a community acquired pneumonia. The relation of antigen detection to the pneumococcal capsular antibody response was also studied.

\section{Patients and methods}

\section{PATIENTS}

The study was performed between April 1987 and October 1989. Ninety patients suspected of having a community acquired pneumonia were included. Pneumonia was defined as an acute illness with fever and one or more transient shadows on the chest radiograph. Patients with lung cancer and immunocompromised patients were excluded.

After diagnosis the patients were classified into the following four groups:

Group 1a-patients with pneumococcal pneumonia, diagnosed by blood culture yielding Streptococcus pneumoniae.

Group $1 \mathrm{~b}$-patients with probable pneumococcal pneumonia, diagnosed on the basis of the finding of lancet shaped Gram positive encapsulated diplococci on Gram stained sputum smears (sputum culture was used to confirm this finding).

Group 2-patients with pneumonia of other known aetiology, defined by a non-pneumococcal pathogen predominant in a Gram stained smear or culture of sputum or by a positive blood culture or a fourfold or greater 
rise or fall in antibody titre in any of the serological tests. Lung infarction presenting as pneumonia was diagnosed on the basis of clinical symptoms and a high probability ventilation-perfusion scan (segmental or larger perfusion defect with ventilation mismatch).

Group 3-patients with mixed bacterial pathogens including $S$ pneumoniae seen in the Gram stained sputum smear and confirmed by culture.

Group 4-patients in whom no positive microbiological or serological results were obtained, the pneumonia being classified as of unknown aetiology.

\section{SPECIMENS}

On admission and during follow up sputum (if available), serum, and urine specimens were collected daily for microbiological and antigen investigation. Three blood samples for aerobic and anaerobic culture were obtained on day one of the study. Pleural fluid was examined when present. Gram staining was performed within a few hours after specimen collection. All specimens were cultured according to conventional methods, including that for Legionella spp. Sputum was stained and cultured for Mycobacterium spp only if clinically indicated. Sputum and oropharyngeal secretions were cultured for respiratory viruses, cytomegalovirus, and Mycoplasma pneumoniae. Acute and convalescent serum samples were assessed by complement fixation tests for $M$ pneumoniae, Chlamydia psittaci, Coxiella burnetii, respiratory viruses, and cytomegalovirus, and by indirect immunofluorescence for Legionella pneumophila (serogroups 1-6). A fourfold or greater rise in titre to $\geqslant 1: 128$ or a single serum titre of $\geqslant 1: 256$ was considered evidence of Legionella infection.

\section{SPUTUM EXAMINATION}

Sputum samples were sequentially washed three times with physiological saline according to Mulder $^{8}$ if they were sufficient for this. The resultant purulent fragments were used for Gram staining and culture. Representative sputum originating from the lower respiratory tract was defined as that containing $\geqslant 50$ leucocytes and $\leqslant 5$ squamous epithelial cells per low power field (total magnification $\times 100$ ). Specimens deviating from this standard were considered to be non-representative specimens and were not included in the results. Cultures were performed semiquantitatively. Bacteria were identified by standard methods.

\section{PNEUMOCOCCAL ANTIGEN DETECTION}

The latex particle agglutination test was performed with the Wellcogen Kit (Wellcome Diagnostics, Dartford, England) according to the manufacturer's instructions. Washed sputum specimens were liquefied and homogenised by adding an equal volume of 1:10 diluted Sputolysin (Stat-Pack, Behring Diagnostics, La Jolla, United States), vortexing for 30 seconds, and leaving them at room temperature for at least 15 minutes. Pleural fluid was treated in the same way except that a quarter volume of diluted Sputolysin was added to the specimen. All other specimens were treated as advised by the manufacturer.

DETERMINATION OF PNEUMOCOCCAL ANTIBODIES Titres of IgG and IgM antibodies against $S$ pneumoniae were measured by enzyme linked immunosorbent assay (ELISA) ${ }^{2122}$ by using polyvalent pneumococcal vaccine (Pneumovax; Merck Sharp and Dohme) containing capsular polysaccharides of the 23 most common pneumococcal types as antigen. A minimal two fold rise or fall in the titre of serum antibodies (IgG or IgM, or both) against pneumococcal capsular polysaccharide was considered significant. ${ }^{21-24}$

\section{STATISTICAL ANALYSIS}

The $\chi^{2}$ test with Yates's correction was used in the analysis of categorical variables. Continuous variables with abnormal distribution were analysed by the Mann-Whitney $U$ test.

\section{Results}

Ninety patients ( 32 women and 58 men, mean (range) age 58.5 (23-89) years) with community acquired pneumonia were included in the study.

\section{MICROBIAL DIAGNOSIS}

A microbial diagnosis was established in $\mathbf{5 3}$ of the 90 patients (table 1). Three patients had lung infarction, and in 34 patients (group 4) no aetiological cause was found for their pneu-

Table 1 Isolated pathogens and numbers of deaths in 90 patients with community acquired pneumonia

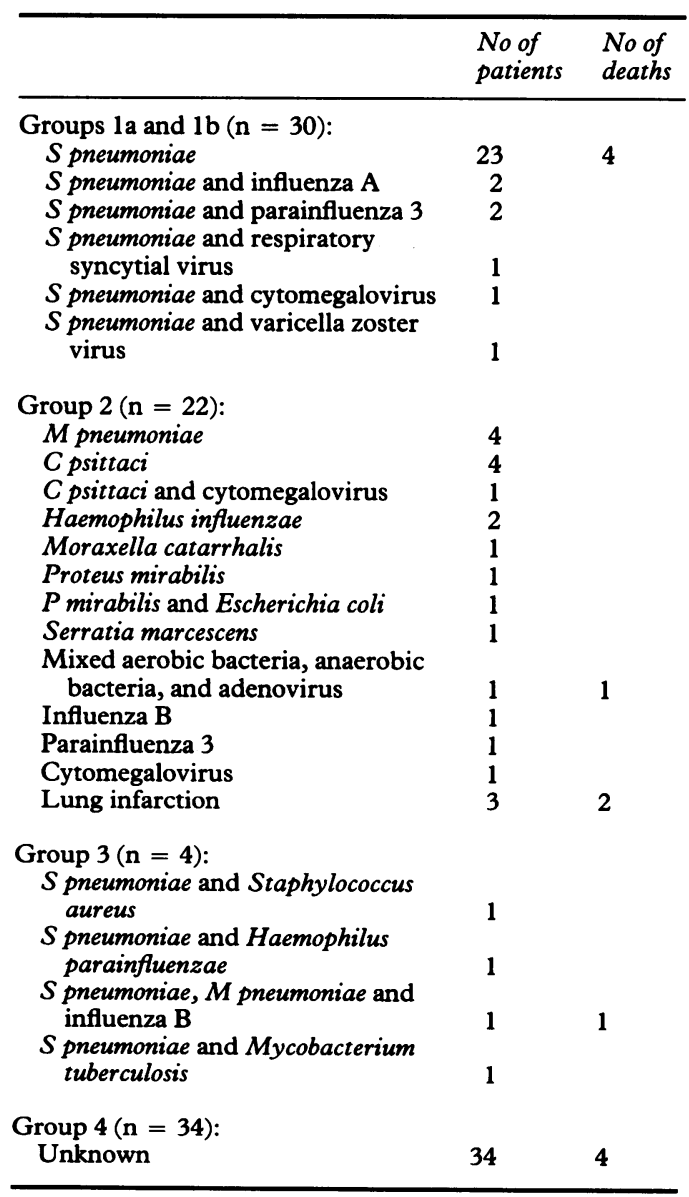


Table 2 Results of various diagnostic tests for pneumococci in 90 patients with community acquired pneumonia

\begin{tabular}{|c|c|c|c|c|c|c|c|c|c|c|c|}
\hline & & \multicolumn{3}{|l|}{ Sputum } & \multicolumn{2}{|l|}{ Blood } & \multirow{2}{*}{$\frac{\text { Urine }}{\text { Antigen }}$} & \multicolumn{3}{|c|}{ Pleural fluid } & \multirow[b]{2}{*}{ Serology } \\
\hline & & $\begin{array}{l}\text { Gram } \\
\text { staining }\end{array}$ & Culture & Antigen * & Culture & Antigen & & $\begin{array}{l}\text { Gram } \\
\text { staining }\end{array}$ & Culture & Antigen & \\
\hline $\begin{array}{l}\text { Groups 1a and 1b } \\
\text { Group 1a } \\
\text { Group 1b } \\
\text { Group 2 } \\
\text { Group 3 } \\
\text { Group 4 }\end{array}$ & $\begin{array}{l}(n=30) \\
(n=14) \\
(n=16) \\
(n=22) \\
(n=4) \\
(n=34)\end{array}$ & $\begin{array}{c}21 / 27 \dagger \\
5 / 11 \\
16 / 16 \\
0 / 16 \\
4 / 4 \\
0 / 26\end{array}$ & $\begin{array}{r}19 / 27 \\
5 / 11 \\
14 / 16 \\
0 / 16 \\
3 / 4 \\
1 / 26\end{array}$ & $\begin{array}{r}23 / 27 \\
8 / 11 \\
15 / 16 \\
2 / 15 \\
3 / 4 \\
12 / 25\end{array}$ & $\begin{array}{c}14 / 27 \ddagger \\
14 / 14 \\
0 / 13 \\
0 / 20 \\
0 / 4 \\
0 / 26\end{array}$ & $\begin{array}{l}3 / 27 \\
3 / 14 \\
0 / 13 \\
0 / 22 \\
0 / 4 \\
1 / 32\end{array}$ & $\begin{array}{l}1 / 30 \\
0 / 14 \\
1 / 16 \\
0 / 22 \\
0 / 4 \\
0 / 34\end{array}$ & $\begin{array}{l}1 / 5 \\
1 / 2 \\
0 / 3 \\
0 / 5 \\
0 / 4\end{array}$ & $\begin{array}{l}0 / 5 \\
0 / 2 \\
0 / 3 \\
0 / 5 \\
0 / 4\end{array}$ & $\begin{array}{l}3 / 4 \\
2 / 2 \\
1 / 2 \\
0 / 2 \\
4 / 4\end{array}$ & $\begin{array}{c}14 / 28 \S \\
7 / 12 \\
7 / 16 \\
3 / 20 \\
1 / 4 \\
9 / 31\end{array}$ \\
\hline
\end{tabular}

*Antigen detection in first representative sputum sample. †Three patients did not expectorate representative sputum. $\ddagger$ In three patients blood culture was not performed. §Convalescent serum samples could not be obtained in two patients who died.

monia. The most commonly isolated microorganism was $S$ pneumoniae. An association with a viral pathogen was found in seven patients in groups $1 \mathrm{a}$ and $1 \mathrm{~b}$. Mixed bacterial infections including $S$ pneumoniae occurred in four patients in group 3.

Pneumococci were identified in Gram stained sputum smears from 21 out of 27 samples in groups $1 \mathrm{a}$ and $1 \mathrm{~b}$, and were cultured from 19 specimens (table 2). Eleven patients with pneumococcal bacteraemia (group 1a) expectorated representative sputum, five specimens of which showed pneumococci in the Gram stained smear and the culture. Pneumococcus was isolated from sputum culture in only one patient in group 4 (patients with pneumonia of unknown aetiology), but was not seen in any of the Gram stained smears.

PNEUMOCOCCAL CAPSULAR ANTIGEN DETECTION On day one of the study 18 of the 30 patients with pneumococcal pneumonia (groups la and 1b) expectorated a representative sputum specimen for Gram staining, culture, and antigen determination. The sensitivity of antigen detection in these patients was $94 \%$. In this group antigen detection in the first available representative sputum specimen collected dur-

No of

patients ing the first week of the illness was positive in 23

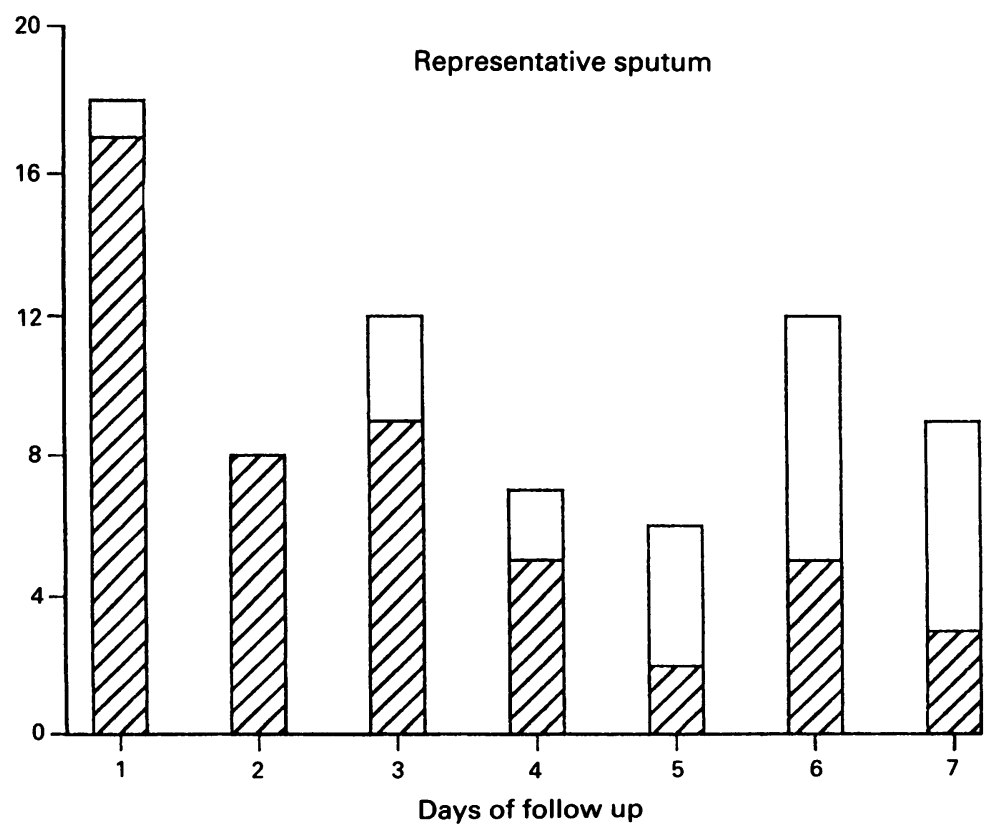

Percentages of the total sputum specimens from patients with pneumococcal pneumonia (groups $1 a$ and $1 b$ ) that were antigen positive during follow up. $\square$ Antigen positive sputum specimens; $\square$ total number of sputum specimens. of 27 patients tested (table 2 ). Three patients failed to expectorate a representative sputum specimen. Antigen detection in sputum specimens (groups 1a and 1b) obtained during the first seven days of the study showed a decrease in the number of antigen positive specimens, although the detection rate of antigen remained high (figure).

Sixteen of the 22 patients with non-pneumococcal pneumonia (group 2) produced one or more representative sputum specimens; antigen was demonstrated in two, giving a specificity for antigen detection of $87 \%$ (table 2). Pneumococcal antigen was detected in representative sputum in three of four patients in group 3 and in 12 of 25 patients in group 4.

In contrast to sputum the rate of antigen detection in serum and urine (often concentrated samples) was very low (table 2). Antigen was detected in pleural fluid, however, in three of the four patients with pneumococcal pneumonia and in all four patients with pneumonia of unknown aetiology.

\section{PNEUMOCOCCAL ANTIBODY DETECTION}

Fourteen of the 28 patients with pneumococcal pneumonia who had convalescent serum samples examined had a significant titre for IgM or IgG or both. One of these patients had no detectable antigen in representative sputum and two patients did not produce sputum. In group 2 (patients with pneumonia of other known aetiology) three of 20 patients had a positive serological response. Nine of the patients with pneumonia of unknown aetiology (group 4) had a positive titre.

\section{ANTIBIOTIC PRETREATMENT}

Four patients with pneumococcal pneumonia had been pretreated with antibiotics (table 3 ). Patients with pneumonia of other known aetiology (group 2) had had antibiotic pretreatment significantly more often $(p<0.0005)$ and for a longer period of time (five versus 1.5 days, $p=0.03$ ) than those with pneumococcal

Table 3 No of patients treated with antibiotics and duration of treatment before admission

\begin{tabular}{lcl}
\hline & $\begin{array}{l}\text { No of } \\
\text { patients } \\
\text { treated }\end{array}$ & $\begin{array}{l}\text { Median (range) } \\
\text { duration of } \\
\text { treatment (days) }\end{array}$ \\
\hline Groups 1a and 1b & $4 / 30$ & $1.5(1-3)$ \\
Group 2 & $17 / 22$ & $5.0(1-14)$ \\
Group 3 & $1 / 4$ & 1.0 \\
Group 4 & $13 / 34$ & $3.0(1-7)$ \\
\hline
\end{tabular}


pneumonia. Patients with pneumonia of unknown aetiology (group 4) had also received antibiotics more often $(p=0.05)$ than those with pneumococcal pneumonia, though not for much longer (three days, $\mathrm{p}=0.09$ ).

\section{Discussion}

Different methods have been used to detect pneumococcal antigen in sputum and other body fluids from patients with pneumonia. We used latex agglutination because it is easy to perform and provides a result within $30 \mathrm{~min}$ utes. Comparison with previous studies is difficult, because of varying antigen detection techniques and different group classifications. ${ }^{1-5}$ The number of patients who were pretreated with antibiotics is also an important variable, perhaps explaining the different proportions of pathogens found in the various studies.

Patients with lung infarction, those with clinical and radiological signs identical to pneumonia, and those with pneumonia caused by a non-pneumococcal pathogen were included in the study to determine the specificity of the antigen detection test. To exclude potential cross reactivity with non-pneumococcal microorganisms mixed infections with $S$ pneumoniae and other bacteria were classified as a separate group.

A microbial aetiology was established by conventional methods in 53 of the 90 patients and, as in most other studies, the most commonly isolated pathogen was $S$ pneumoniae. ${ }^{1-5}$

Our results suggest that the pneumococcal antigen test is a reliable method for increasing the number of correct diagnoses in patients with community acquired pneumonia. In representative sputum a sensitivity of $94 \%$ (groups 1a and 1b) and a specificity of $87 \%$ (group 2) were established. The antigen test result remained positive during treatment with antibiotics. This observation confirms that a positive result is not dependent on viable pneumococci and is useful in patients treated with antibiotics before admission to hospital. Some patients did not expectorate representative sputum on admission, but did later, possibly because of improvement in performance, decrease in pleural pain, or the effect of bronchodilators. Antigen detection was performed on washed representative sputum samples in only two other studies, but antigen detection during the course of the illness was not reported. ${ }^{25} 26$

Two positive antigen reactions occurred in sputum samples in group 2 . In one patient, who was pretreated with antibiotics, a viral aetiology was established, although pneumococcal infection may also have been involved. The other patient, who had a serologically proved influenza $B$ infection, had difficulty expectorating because of severe pleuritic pain and pneumococcus may have been missed in scanty sputum. This mixed control group, chosen for logistic reasons, was not an ideal group for determination of the specificity of the test. Sputum washing may increase the specificity of the antigen detection test by decreasing the number of oropharyngeal cross reacting microorganisms. ${ }^{102728}$

The value of antigen detection, especially in patients already treated with antibiotics before hospital admission, was also seen in patients with pneumonia of unknown aetiology (group 4). The observation that antigen detected in a large proportion of this group suggests that these patients probably had a pneumococcal pneumonia. Conventional microbiology rarely gives a definitive diagnosis in patients receiving antibiotics before admission. Our results suggest that in such patients detectable antigen gives an indication of the cause of the pneumonia.

The yield of positive antigen detection by latex agglutination in serum and urine specimens was low, which is in agreement with previous studies. ${ }^{11} 1329$ One reason for this may be a low antigen concentration in these fluids. Lower concentrations of antigen may be detected by coating the latex particles with monospecific (one serotype only) antibodies, but this technique is not realistic for diagnostic purposes as it is time consuming and expensive..$^{30}$ Methods such as counterimmunoelectrophoresis and ELISA seem to be more sensitive for use in blood and urine, but examination of sputum by these techniques remains superior. ${ }^{11} 13$

Although the number of specimens tested was small, antigen detection in pleural fluid was remarkably high in patients with pneumococcal pneumonia or pneumonia of unknown aetiology. This high rate of antigen detection in pleural fluid has been reported only with counterimmunoelectrophoresis. ${ }^{3132}$

Pneumococcal serology may be of additive value but cannot help to establish an early diagnosis. The sensitivity of $50 \%$ and specificity of $85 \%$ are similar to those in other studies. ${ }^{22} 33$ Pneumococcal typing was not done in all patients, so we do not know whether all the types isolated were present in Pneumovax 23. The highest percentage of positive serological results was in patients with bacteraemia (group 1a). In contrast with antigen detection, serological results were conclusive in only three patients with pneumococcal pneumonia and four patients with pneumonia of unknown aetiology. Our study shows that pneumococcal serological testing is less sensitive than antigen detection in sputum but may be helpful in patients who do not expectorate representative sputum.

Thirty five $(39 \%)$ patients received antibiotics before admission to hospital, and this is comparable with proportions in other studies. ${ }^{2526}$ Patients with pneumonia of other known aetiology (group 2) were pretreated more often and for a longer period of time. Most patients in this group had not had an acute onset to the illness and had received inappropriate antibiotic treatment before admission.

Pneumococcal antigen determination in representative sputum is of value in addition to Gram staining and culture for the diagnosis of pneumococcal pneumonia. The latex agglutination test is a rapid and reliable method for detecting antigen in sputum and is able to 
demonstrate antigen in sputum specimens obtained during antibiotic treatment. Antigen testing of pleural fluid may complement the sputum tests, but the results of antigen detection in urine and serum samples were disappointing. Pneumococcal serological testing is far less sensitive than antigen detection but may be of value in the absence of sputum.

This study was supported in part by Wellcome Diagnostics, Dartford, England.

1 Macfarlane JT, Finch RG, Ward MJ, Macrae AD. Hospital study of adult community-acquired pneumonia. Lancet 1982;ii:255-8.

2 British Thoracic Society Research Committee. Communityacquired pneumonia in adults in British hospitals in 19821983: a survey of aetiology, mortality, prognostic factors and outcome. $Q J$ Med 1987;62:195-220.

3 White RJ, Blainey AD, Harrison KJ, Clarke SKR. Causes of pneumonia presenting to a district general hospital Thorax 1981;36:566-70.

4 Marrie TJ, Durant H, Yates L. Community-acquired pneumonia requiring hospitalization: 5-year prospective study. Rev Infect Dis 1989;2:586-99.

5 Lim I, Shaw DR, Stanley DP, Lumb R, McLennan G. A prospective hospital study of the aetiology of curn.:-inityacquired pneumonia. Med J Aust 1989;151:87-91.

6 Murray PR, Washington II JA. Microscopic and bacteriologic analysis of expectorated sputum. Mayo Clin Proc 1975;50:339-44.

7 Kalin M. Bacteremic pneumococcal pneumonia: value of culture of nasopharyngeal specimens and examination of washed specimens. Eur J Clin Microbiol 1982;1:394-6.

8 Mulder J. Clinical significance of bacteriologic examination of sputum in cases of acute and chronic bacterial disease of respiratory tract. In: Dock W, Snappert I, eds. Advances in Internal Medicine. Vol 12. Chicago Year Book, Medical Publishers, 1964:223-55.

9 Mulder J, Goslings WRO, Van der Plas MC, Lopez Cardozo $P$. Studies on the treatment with antibacterial drugs of acute and chronic mucopurulent bronchitis caused by Haemophilus influenzae. Acta Med Scand 1952;143: $32-49$.

10 Bartlett JG, Finegold SM. Bacteriology of expectorated sputum with quantitative culture and wash technique compared to transtracheal aspirates. Am Rev Respir Dis 1978;117:1019-27.

11 Cerosaletti KM, Roghmann MC, Bentley DW. Comparison of latex agglutination and counterimmunoelectrophoresis for detection of pneumococcal antigen in elderly pneumonia patients. J Clin Microbiol 1985;22:553-7.

12 Guzzetta P, Toews GB, Robertson KJ, Pierce AK. Rapid diagnosis of community-acquired bacterial pneumonia. Am Rev Respir Dis 1983;128:461-4.

13 Lenthe-Eboa S, Brighouse G, Auckenthaler R, et al. Comparison of immunological methods for diagnosis of pneumococcal pneumonia in biological fluids. Eur J Clin Microbiol 1987;6:28-34.

14 Ajello GW, Bolan GA, Hayes PS, et al. Commercial latex agglutination tests for detection of Haemophilus influenzae type b and Streptococcus pneumoniae antigens in patients with bacteremic pneumonia. J Clin Microbiol 1987;25:1388-91.
15 Leach RP, Coonrod JD. Detection of pneumococcal antigens in the sputum in pneumococcal pneumonia. Am Rev Respir Dis 1977;116:847-51.

16 Edwards EA, Coonrod JD. Coagglutination and counterimmunoelectrophoresis for detection of pneumococcal antigens in the sputum of pneumonia patients. J Clin Microbiol 1980;11:488-91.

17 Holmberg H, Holme T, Krook A, Olsson T, Sjöberg L, Sjögren AM. Detection of C polysaccharide in Streptococcus pneumoniae in the sputa of pneumonia patients by an enzyme-linked immunosorbent assay. JClin Microbiol 1985;22:111-5.

18 Kalin M, Lindberg AA, Olausson E-H. Diagnosis of pneumococcal pneumonia by coagglutination and counterimmunoelectrophoresis of sputum samples. Eur J Clin Microbiol 1982;1:91-6.

19 Tebbutt GM, Coleman DJ. Evaluation of some methods for the laboratory examination of sputum. J Clin Pathol 1978;31:724-9.

20 Whitby M, Kristinsson KG, Brown M. Assessment of rapid methods of pneumococcal antigen detection in routine sputum bacteriology. J Clin Pathol 1985;38:341-4.

21 Snijder JAM, Löwenberg A, Klompmaker I, Weits J. Pneumococcal antibodies measured with a rapid enzymelinked-immunosorbent assay (ELISA), using the whole vaccine as antigen. Suggestions for clinical application. Neth J Med 1988;33:52-9.

22 Löwenberg A, Snijder JAM, vd Weele Th, Sluiter HJ. Pneumococcal antibody levels in patients with acute lung infiltrates. Infection 1987;15:192-9.

23 Russell H, Edwards LR, Wortham EW, Facklam RR Enzyme-linked immunosorbent assay for detection of antibodies against Streptococcus pneumoniae capsular polysaccharides. J Clin Microbiol 1980;11:198-9.

24 Pedersen FK, Henrichsen J. Detection of antibodies to pneumococcal capsular polysaccharides by enzyme-linked immunosorbent assay. J Clin Microbiol 1982;15:372-8.

25 Kalin M, Lindberg AA. Diagnosis of pneumococcal pneumonia: a comparison between microscopic examination of expectorate, antigen detection and cultural procedures. Scand J Infect Dis 1983;15:247-55.

26 Örtqvist A, Jönsson I, Kalin M, Krook A. Comparison of three methods for detection of pneumococcal antigen in sputum of patients with community-acquired pneumonia. sputum of patients with community-acquired p.

27 Holmberg H, Danielsson D, Hardie J, Krook A, Whiley R. Cross-reactions between $\alpha$-streptococci and omniserum, a polyvalent pneumococcal serum, demonstrated by direct immunofluorescence, immunoelectro-osmophoresis, and latex agglutination. J Clin Microbiol 1985;21:745-8.

28 Sjögren AM, Holmberg H, Krook A. Etiologic diagnosis of pneumonia by antigen detection: crossreactions between pneumococcal C-polysaccharide and oral microorganisms. Diagn Microbiol Infect Dis 1987;6:239-48.

29 Woodhead MA, Macfarlane JT, McCracken JS, Rose DH, Finch RG. Prospective study of the aetiology and outcome of pneumonia in the community. Lancet 1987; i:671-4.

30 O'Neill KP, Lloyd-Evans N, Campbell H, Forgie IM, Sabally S, Greenwood BM. Latex agglutination test for diagnosing pneumococcal pneumonia in children in developing countries. BMJ 1989;298:1061-4.

31 Tugwell $\mathrm{P}$, Greenwood BM. Pneumococcal antigen in lobar pneumonia. J Clin Pathol 1975;28:118-23.

32 Coonrod JD, Wilson HD. Etiologic diagnosis of intrapleura empyema by counterimmunoelectrophoresis. Am Rev Respir Dis 1976;113:637-41.

$33 \mathrm{Kalin}$ M, Lindberg AA. Antibody response against the type specific capsular polysaccharide in pneumococcal pneumonia measured by enzyme linked immunosorbent assay. Scand J Infect Dis 1985;17:25-32. 